\title{
Model Experiment and Its Analysis on Circulating Continuous Degassing*
}

\author{
By Takuya UEDA,** Sadao FURUYAMA ${ }^{* * *}$ and Ryuichi NAKAGAWA***
}

\section{Synopsis}

(1) Residence time distribution function $E(t)$ in a continuous degassing reactor is theoretically derived from the assumption that the mixing in the vessel is expressed as a circulation model with plug flow and perfect mixing. The equation is shown as follows:

$$
\begin{gathered}
E(t)=d \sum_{n=0}^{\infty} \frac{b^{n}}{n !}\{t-(h+n c)\}^{n} \cdot \exp [-a\{t-(h+n c)\}] \\
t \geqq h+n c
\end{gathered}
$$

Where the coefficients are shown as follows:

$$
\begin{aligned}
\theta_{\mathrm{C}} & =\frac{V_{1}}{v_{1}}, \quad \theta_{\mathrm{B}}=\frac{V_{2}}{v_{2}}, \quad a=\frac{1}{(1-p) \theta_{\mathrm{C}}}, \quad b=\frac{v_{2}}{v_{1}(1-p) \theta_{\mathrm{C}}} \\
c & =p \cdot \theta_{\mathrm{C}}+\theta_{\mathrm{B}}, \quad d=\frac{v}{v_{1}(1-p) \theta_{\mathrm{C}}}, \quad h=p \cdot \theta_{\mathrm{C}}
\end{aligned}
$$

and $p$ is the plug flow ratio in the vacuum vessel.

These coefficients were determined by the flow rate at the inlet $v$, the circulating rate $v_{1}$, the real flow rate in the flow vessel $v_{2}$, the volume of the vacuum vessel $V_{1}$, and the volume of the flow vessel $V_{2}$.

(2) Mixing characteristics in a model apparatus were measured by the concentration pulse responses under the similarity of Fr and Re numbers.

The results of the measurement of the pulse responses and the tracing of the flow pattern showed the presence of minor part of bypassing and dead space, and were in a relatively close agreement with the above-mentioned theoretical equation.

(3) From these results, the percent conversion of continuous degassing under the assumption of perfect mixing in reactors was estimated. It was in approximate agreement with the results of RH degassing process when the mean residence time was properly selected and at least two unit reactors were connected in series.

\section{Introduction}

In National Research Institute for Metals, researches on the continuous steelmaking have been carried out with fairly successful results. ${ }^{1-7)}$ In order to supply continuously the molten steel to a continuous casting machine, a finishing unit, especially a vacuum degassing unit should be combined with the refining process.

Batch degassing of molten steel has been commercially performed as seen in processes of $\mathrm{RH}, \mathrm{DH}$, ladle, etc. ${ }^{8)}$ and many reports on the mixing and the reaction in them have been published. ${ }^{8-17}$ ) A few patents on the continuous degassing reactor have been published in Japan, ${ }^{18)}$ Germany, ${ }^{19)}$ and U.S.A. ${ }^{20}$ Researches for the mixing in batch degassing reactors were mainly carried out on the relations of degrees of mixing with time progress, ${ }^{21}$ ) and there are few reports in which the dynamic characteristics of the continuous degassing reactor have been discussed. If a reaction mechanism in batch processes is known, the percent conversion in the continuous operation at certain specified variables of the operation can be, in general, estimated from the combination of the percent conversion in batch processes with the mixing characteristics of the continuous ones.

Our water model test has shown the effect of such factors as volume of the circulating vessel, circulating rate in the circulating vessel and flow rate in the flow vessel on the mixing characteristics in the reactor. Then we have proposed a mathematical model of the residence time distribution in continuous degassing reactor with inner circulation.

\section{Selection of the Experimental Reactor}

Various kinds of vacuum degassing reactors have been operated in batch mode. In these processes, the degassing reactor with inner circulation is considered to be suited to continuous operation system, because the movable parts of it are smaller than the others, and the bath temperature drop is comparatively small. The continuous vacuum degassing reactor may be classified into the following four types as shown in Fig. 1.

(1) A normal $\mathrm{RH}$ vacuum degassing reactor (tank reactor) is merely changed into a continuous reactor ((1) in Fig. 1).

(2) Circulating vessels are arranged in series on the flow vessel of trough type. The one case is without skimmers in the flow vessel ((2) in Fig. 1) and the other is with skimmers ((3) in Fig. 1).

(3) The circulating vessel is used as the connect-

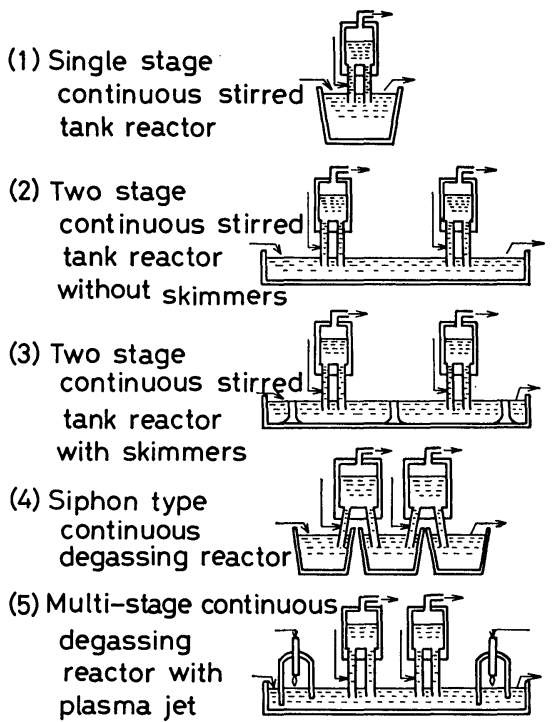

Fig. 1.

Variations of continuous degassing reactor.

* Originally published in Tetsu-to-Hagané, 66 (1980), 478, in Japanese. English version received September 8, 1980.

** Formerly National Research Institute for Metals. Now at Fuji Standard Research, Inc., Uchisaiwai-cho, Chiyoda-ku, Tokyo 100.

*** National Research Institute for Metals, Nakameguro, Meguro-ku, Tokyo 153. 
ing tube between two neighboring flow vessels. Degassing is carried out during once-through passage of the molten steel. Therefore, circulation is not performed in this arrangement ((4) in Fig. 1).

(4) Plasma equipments are added to the abovementioned reactor inside or outside the circulating vessel ((5) in Fig. 1).

In the type (1), the reactor is verified to be of approximately perfect mixing. ${ }^{11}$ In the types (2) and (3), the mixing characteristics must be measured and analyzed theoretically. In the type (4), the degassing is finished during once-through passage in the circulating vessel. In this case, it is specifically necessary to install some devices which enables to increase the capacity coefficient in the reactor. Therefore, this paper was limited to the study of the type (2) reactor.

In model experiment, the similarity criteria between the prototype and the model must be established. It is well-known that the main dimensionless numbers concerning to the flow are Re number relating to viscosity, $\mathrm{Fr}$ number relating to gravity, and We number relating to surface tension. It is impossible for these three criteria to be satisfied simultaneously. Then, $R e$ number and $F r$ number have been assumed to be more important to the flow than We number. Assuming an isothermal and uniform reactor, Eq. (1) is obtained from a simple dimension analysis.

$$
\frac{L}{L^{\prime}}=\left(\frac{\rho^{\prime} \cdot \mu}{\rho \cdot \mu^{\prime}}\right)^{2 / 3}
$$

where,

$L:$ linear dimension of the model

$\mu$ : viscosity of water $\left(1.0 \text { c.p. at } 20^{\circ} \mathrm{G}\right)^{25)}$

$\rho$ : density of water $\left(1.0 \mathrm{~g} / \mathrm{cm}^{3} \text { at } 20^{\circ} \mathrm{G}\right)^{25)}$

$L^{\prime}$ : linear dimension of the real reactor

$\mu^{\prime}:$ viscosity of molten steel $\left(6.0 \text { c.p. at } 1600^{\circ} \mathrm{C}\right)^{24)}$

$\rho^{\prime}$ : density of molten steel $\left(6.8 \mathrm{~g} / \mathrm{cm}^{3} \text { at } 1600^{\circ} \mathrm{C}\right)^{24)}$

The ratio 1.08 is calculated by substituting the above physical constants into Eq. (1); the size of the water model reactor must be almost equal to that of the real reactor to meet the similarity on Re number and $F r$ number.

\section{Approximate Model of the Mixing Charac- teristics in Continuous Degassing Reactor}

In general, there exist simultaneously fractions of dead space, bypass flow, perfect mixing and plug flow in the real reactor. Various mixed models have been proposed and the residence time distribution function to each model have been derived mathematically. ${ }^{26,27)}$ If there is not great difference of the discharge concentration between the practical and the model equipments, and if a little error is permitted, the theoretical residence time distribution function may be said to have an applicability enough for the practical use by adopting the mixed model that is appropriately combined from a view point of the reactor structure. ${ }^{26)}$

A special reactor such as the continuous degassing reactor with a circulating equipment which is con- sidered to be a sort of the stirrer, has many parameters. When the residence time distribution function is derived explicitly, all these parameters must be included.

In derivation of the theoretical formula, the following assumptions were made. The names of the parts of the reactor are described in Fig. 8 as shown later.

(1) The mixing in the circulating vessel is given approximately by a sequential combination of the plug flow region with the perfect mixing region. It is assumed that the plug flow is dominant in the upleg and the down-leg of the circulating vessel, and that perfect mixing is dominant in the vacuum vessel of the circulating vessel.

(2) Plug flow is dominant in the flow vessel. This model is equivalent to the stirred vessel with internal circulation of a high speed. The dead space and the bypass flow are neglected.

The experimental variables in derivation of the mathematical model are the volume of the circulating vessel, the circulating rate in the circulating vessel, the volume of the flow vessel and the flow rate in it. The fraction of plug flow in the circulating vessel is determined by the ratio of the volume of the legs to the volume of the circulating vessel. And there are two kinds of the leg arrangement; that is, the one is the case in which the up-leg is placed on the inlet side of the flow vessel and the other is the case in which the up-leg is in the outlet side. The mixed models and the block diagrams are shown in Fig. 2 and Fig. 3, respectively.

When the up-leg of the circulating vessel is positioned in the inlet side of flow vessel as seen in Fig. 2, the transfer function $W_{1}(s)$ shown as follows.

$$
W_{1}(s)=d \sum_{n=0}^{\infty} \frac{b^{n} \cdot \exp \{-(h+n c) s\}}{(s+a)^{n+1}}
$$

The derivation of Eq. (2) is given in the supplement equation (S-7). The residence time distribution function $E(t)$, namely, the impulse response is given by inverse Laplace transformation $L^{-1}\left\{W_{1}(s)\right\}$ as follows.

$$
\begin{aligned}
E(t)= & L^{-1}\left\{W_{1}(s)\right\}=d \sum_{n=0}^{\infty} \frac{b^{n}}{n !}\{t-(h+n c)\}^{n} \\
& \times \exp [-a\{t-(h+n c)\}] \quad t \geqq h+n c \ldots .
\end{aligned}
$$

When the up-leg of the circulating vessel is positioned in the outlet side of the flow vessel as seen in Fig. 3, the transfer function $W_{2}(s)$ is shown as follows.

$$
W_{2}(s)=\frac{v}{v_{2}} \exp \left(-\theta_{B} \cdot s\right)+D \sum_{n=0}^{\infty} \frac{B^{n} \cdot \exp \{-(H+n C) s\}}{(s+A)^{n+1}}
$$

The derivation of Eq. (4) is given in Eq. (S-11), namely, the impulse response is given by $L^{-1}\left\{W_{2}(s)\right\}$ as follows.

$$
\begin{aligned}
E(t)= & L^{-1}\left\{W_{2}(s)\right\}=\frac{v}{v_{2}} \delta\left(t-\theta_{\mathrm{B}}\right)+d \sum_{n=0}^{\infty} \frac{b^{n}}{n !} \\
& \times\{t-(H+n C)\}^{n} \cdot \exp [-A\{t-(H+n C)\}] \\
& t \geqq H+n C \ldots \ldots \ldots \ldots \ldots \ldots \ldots \ldots \ldots \ldots \ldots \ldots \ldots \ldots \ldots \ldots
\end{aligned}
$$



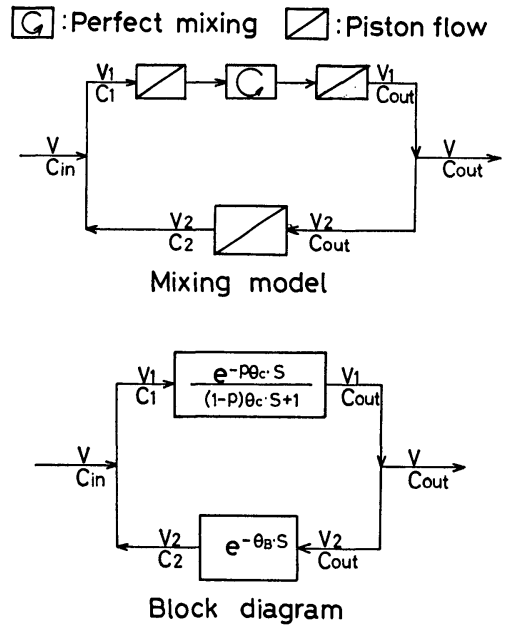

Fig. 2. Mixing model of stirred reactor with inner circulation. (Up-leg is placed on the inlet side of the flow vessel.)

If the mean residence time for the whole reactor is $\theta$, and dimensionless time is $t / \theta$, a relation of $E(t)$ with $E(t / \theta)$ is given as follows.

$$
\theta \cdot E(t)=E\left(\frac{t}{\theta}\right)
$$

If we plot $\theta \cdot E(t)$ against $t / \theta$ for various specified conditions, the curves must be as in from Fig. 4 to Fig. 7. Figures 4 and 5 were obtained from Eq. (3), and Figs. 6 and 7 from Eq. (5).

The shapes of the residence time distribution function in Figs. 4 and 5 are different from those in Figs. 6 and 7.

The $\delta$ function $\left(\left(v / v_{2}\right) \delta\left(t-\theta_{\mathrm{B}}\right)\right)$ appears in the position equivalent to $\theta_{\mathrm{B}}$ (shown in Eq. (S-11) of Supplement) when the up-leg is positioned in the outlet side of the flow vessel.

The $\delta$ function can show only the position by its definition, and cannot show the height. Since the practical pulse input has a very narrow width, its resultant response comes to have a limited width, and the integral value of the $\delta$ function $v / v_{2}$ (flow rate $v /$ (flow rate $v$ +circulating rate $v_{1}$ )) appears in this position within a finite time with a certain width. Theoretically, this integral value and the area occupied below the successive curve make 1 . The value of $v / v_{2}$ is shown in Table 1 . When the circulating rate and the ratio of the circulating rate to the flow rate are large, Eqs. (3) and (5) almost coincide together and may be treated as perfect mixing.

\section{Experiment}

\section{Experimental Reactor}

The experimental reactor, as shown in Fig. 8, is composed of a flow vessel, a circulating vessel, a water jet ejector for generation of vacuum, and a gas lift. The flow vessel is of through type, with the size of $26 \mathrm{~cm}(25 \mathrm{~cm})$ in wide, $60 \mathrm{~cm}(20 \mathrm{~cm})$ in height, $96 \mathrm{~cm}(95 \mathrm{~cm})$ in length, and its real hold-up is $48 l$. The numbers shown in the parentheses are inside sizes of the vessel in which water is held. The size
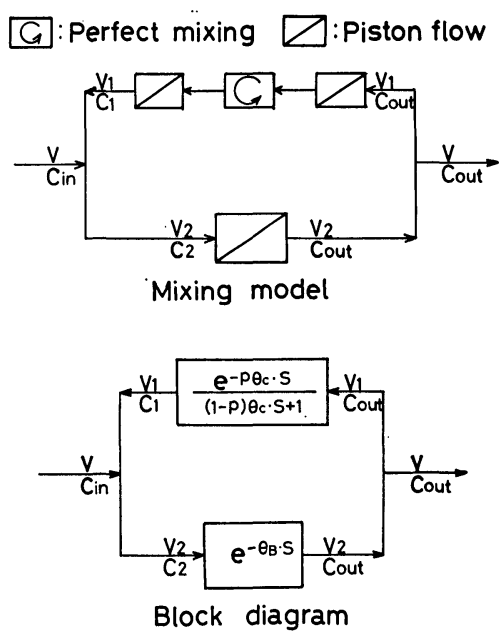

Fig. 3. Mixing model of stirred reactor with inner circulation. (Up-leg is placed on the outlet side of the flow vessel.)

of the vacuum vessel in the circulating vessel is $50 \mathrm{~cm}$ $(48 \mathrm{~cm})$ in length, $28 \mathrm{~cm}(26 \mathrm{~cm})$ in width, $96 \mathrm{~cm}$ $(64 \mathrm{~cm})$ in height, and the up-leg and down-leg are $9 \mathrm{~cm} \phi \times 73 \mathrm{~cm}$. The real hold-up of the vacuum vessel and of the legs are $80 l$ and $10 l$, respectively.

The circulating rate was measured with an orifice flow meter, which is set in the middle of the down-leg and has a measurable range from $20 \mathrm{l} / \mathrm{min}$ to $150 \mathrm{l} / \mathrm{min}$ by exchanging the orifices $(40 \mathrm{~mm} \phi, 50 \mathrm{~mm} \phi, 60 \mathrm{~mm} \phi)$. The water jet ejector has an exhaust capacity of $7 \mathrm{~m}^{3} / \mathrm{h}$. The gas lift is constituted of a nozzle $(1.3 \mathrm{~cm} \phi)$ fitted with porous metal plate and a pressurized gas holder, and is placed inside and quite near the entrance of the up-leg. The regulation of the driving gas $\mathrm{N}_{2}$ of the gas lift was carried out by manual so as to attain the designated circulating rate in the above-mentioned flow meter.

The flow rate of fed water was measured by another orifice meter capable of measuring the maximum value of $30 \mathrm{l} / \mathrm{min}$. A photoelectric spectrophotometer combined with a continuous sampler was used for the continuous colorimetry of tracer concentration.

The circulating vessel and the flow vessel were made of transparent synthetic resins.

\section{Experimental Method}

Sawdust was used as a visible tracer for visualization of the flow pattern in the flow vessel.

Red color dye, safranine $T$, was used as a concentration tracer for the measurement of the mixing characteristics by means of the concentration pulse response. The concentration of the outlet flow which was branched at the outlet position of the flow vessel was continuously measured and recorded by means of spectrocolorimetry with a wave length of $570 \mu \mathrm{m}$.

The experimental procedure was as follows. The safranine $T$ solution of $3 \mathrm{~g}$ was poured into the flow inlet, when the flow became steady. The steady state means that the water level of the vacuum vessel is $140 \mathrm{~cm}$ higher than the water level of the flow vessel at the specified values of the flow rate and the 


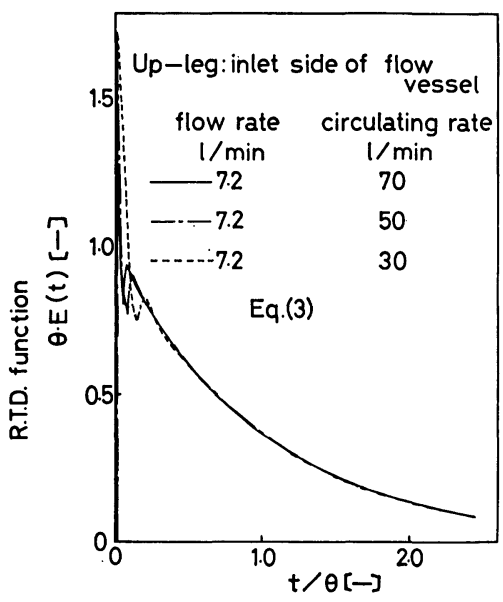

Dimensionless time

R.T.D.: Residence Time Distribution

Fig. 4. Theoretical residence time distribution function in continuous degassing reactor.

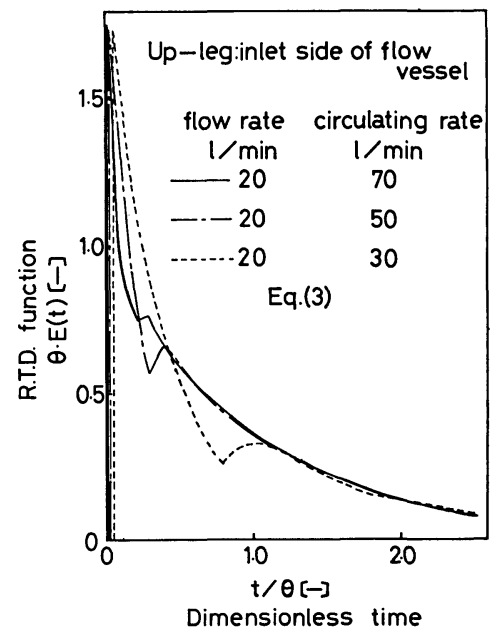

Fig. 5. Theoretical residence time distribution function in continuous degassing reactor.

Table 1. Calculated values of $v / v_{2}$. (Integral values of $\delta$ function in Eq. (5))

\begin{tabular}{c|cccc}
\hline$v_{1}(l / \mathrm{min})$ & 30 & 50 & 70 & 200 \\
$v(l / \mathrm{min})$ & & & & \\
\hline 7.2 & 0.195 & 0.126 & 0.094 & 0.035 \\
20 & 0.400 & 0.286 & 0.222 & 0.091
\end{tabular}

circulating rate. The required time for pouring the tracer solution was from $2 \mathrm{~s}$ to $3 \mathrm{~s}$, and it was very short in comparison with the mean residence time in this experiment.

This experimental method may be said "pulse response".

\section{Experimental Variables}

The circulating rates were set at $30 \mathrm{l} / \mathrm{min}, 50 \mathrm{l} / \mathrm{min}$ and $70 \mathrm{l} / \mathrm{min}$, and the flow rates were adjusted at 7. $2 \mathrm{l} / \mathrm{min}$ and $20 \mathrm{l} / \mathrm{min}$. The hold-up of the flow vessel was almost unchanged in the region of the flow rates of $7.2 \sim 20 \mathrm{l} / \mathrm{min}$. The flow in both the up-leg and the vacuum vessel was of gas-liquid mixed

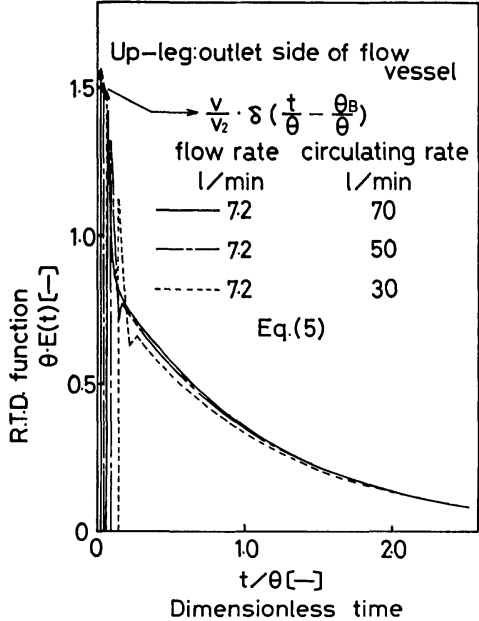

Fig. 6. Theoretical residence time distribution function in continuous degassing reactor.

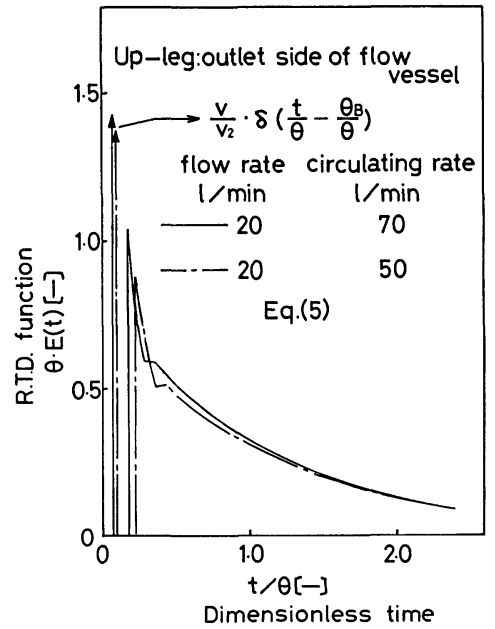

Fig. 7. Theoretical residence time distribution function in continuous degassing reactor.

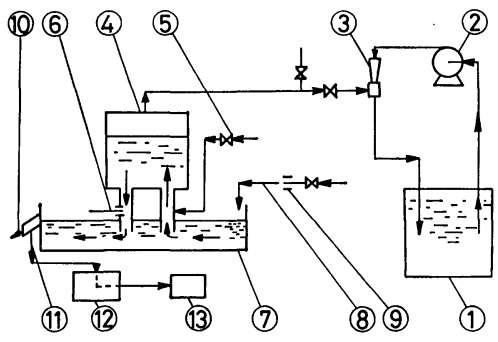

$\begin{array}{llll}\text { (1) Water tank } & \text { (2) } & \text { Pump } \\ \text { (3) Ejector } & \text { (4) } & \text { Circulating vessel } \\ \text { (5) Gas lift } & \text { (6) } & \text { Flow meter } \\ \text { (7) } & \text { Flow vessel } & \text { (8) } & \text { Water inlet } \\ \text { (9) } & \text { Flow meter } & \text { (10) } & \text { Water outlet } \\ \text { (11) } & \text { Continuous sampler } & \text { (12) } & \text { Photoelectric } \\ \text { (13) Recorder } & & \text { photometer }\end{array}$

Fig. 8. Model equipment for continuous degassing process.

phase when being circulated, and the hold-up in the vacuum vessel varied to a small extent according to the circulating rate. The up-leg of the circulating vessel was placed at either the inlet side or the outlet side of the flow vessel. The relative position of the circulating vessel and the flow vessel was fixed, the 
position of the circulating vessel was put at the center of and above the flow vessel.

\section{Experimental Results}

\section{Flow Pattern in the Vessel Visualized by Solid Tracer}

It may be safely said that the flow pattern in both the up-leg and the down-leg of the $\mathrm{RH}$ degassing reactor is of plug flow and the one in the vacuum vessel is of perfect mixing. ${ }^{11)} \quad$ This state is considered to be unchanged even in the continuous operation. In the flow vessel of the continuous degassing reactor, the flow pattern is very complicated because of the effect of the circulating flow in the circulating vessel. It is necessary to know by observation what kind of flow is really dominant in order to construct a mathematical mixing model (a residence time distribution function).

Necessary properties of the solid tracer for the visualization of the flow are as follows.

(1) The density of the solid tracer is approximately equal to that of used liquid (water in this case); namely, the sedimentation rate of the solid tracer in the water piller is very slow.

(2) It is necessary for the solid tracer to have a large size to a certain degree and not to show geometrical anisotropy, because the loci of the particles are photographically measured. The sawdust was sized from 0.5 to $1.0 \mathrm{~mm}$, and the sawdust swollen with water for 5 min showed an average time of $52 \mathrm{~s}$ for sedimentation through the water pillar of $20 \mathrm{~cm}$; the sedimentation rate is $0.38 \mathrm{~cm} / \mathrm{s}$. Because the sedimentation rate of the sawdust shows a value below $1 / 10$ of the flow rate, as mentioned later, it is concluded that this swollen sawdust is suitable as the solid tracer.

The movement of the tracer in the flow vessel was photographed with a shutter speed of $1 \mathrm{~s}$ for a steady state flow rate of $20 \mathrm{l} / \mathrm{min}$ (nominal flow velocity $0.67 \mathrm{~cm} / \mathrm{s}$ ) and a circulating rate of $50 \mathrm{l} / \mathrm{min}$ (nominal flow velocity in leg $10.6 \mathrm{~cm} / \mathrm{s}$ ), when the vacuum vessel level from flow vessel level is $140 \mathrm{~cm}$. The loci and the moving velocities of the solid tracers were obtained from the enlarged photograph, and the sketch of the flow pattern on a two dimensional vertical plane in the flow vessel is shown in Fig. 9. Figure 9 shows that tracer velocities in the flow vessel are from $3 \mathrm{~cm} / \mathrm{s}$ to $6 \mathrm{~cm} / \mathrm{s}$, which are approximately ten times as large as the nominal velocity of $0.67 \mathrm{~cm} / \mathrm{s}$ in the flow vessel. This fact shows that a severe mixing is dominant in the flow vessel, and supports the assumption that continuous degassing reactors are " continuous stirred tank reactors with the inner circulation of a high speed" as mentioned in Chapter III.

\section{Visualization of Flow by Concentration Tracer}

Though the loci of the particles by means of the solid tracer visualize the flow during a short time, the behavior of the flow during the whole period is not quite clear. Thus, the details of the flow in the flow vessel and in the circulating vessel corresponding to the lapse of time were observed by pursuing the movement of poured safranine solution.

When the concentration tracer is softly poured into the quiescent dead water at the inlet side of the flow vessel, the dyestuff is diluted and diffuses slowly from the inlet side to the outlet side of the flow vessel, and the tone of safranine in the flow vessel becomes approximately uniform within the sensitivity of naked eye after the lapse of 12 to $13 \mathrm{~min}$. When no circulation is carried out in the circulation vessel, the moving direction of the flow at the upper part in the flow vessel is different from the one at the lower part at the steady flow rate of $7.2 \mathrm{l} / \mathrm{min}$ (the flow velocity $14.4 \mathrm{~cm} / \mathrm{min}$ ). The circulation of the flow, which runs from the inlet side towards the outlet side on the bottom and from the outlet side towards the inlet side on the upper surface, generates in the flow vessel and the tone of the color in the flow vessel becomes uniform after the lapse of 10 to $15 \mathrm{~s}$, which is 2.5 to $3.75 \%$ of the calculated mean residence time of $6.7 \mathrm{~min}$. The mixing in the flow vessel is not a simple plug flow, but a considerably violent flow. The movement of the dyestuff was photographed every $5 \mathrm{~s}$ for a circulating rate of $50 \mathrm{l} / \mathrm{min}$ and a flow rate of $20 \mathrm{l} / \mathrm{min}$ (the up-leg is placed at the inlet side of flow vessel). From these observations it may be safely said that the plug flow is dominant in both the up-leg and the down-leg, and that the perfect mixing is dominant in the vacuum vessel. Comparing with the mean residence time of $1.8 \mathrm{~min}$, only a short period of $15 \mathrm{~s}$ is required for the dye to become uniform. These results, also, support the assumption that the continuous degassing reactor is "the continuous stirred tank reactor with the inner circulation of a high speed" as mentioned in Cahpter III.

\section{Results of the Residence Time Distribution Measured by Means of Concentration Pulse Response}

The mixing in the reactor is estimated from the shape of the pulse response curve ( $E$ curve) using the following information. ${ }^{28)}$

(1) In a relatively small degree of the mixing the peak almost appears at the reduced mean residence time $t / \theta=1$.

(2) When a region of the vessel, which retains the fluid elements for a certain duration longer than the mean residence time of the total fluid, may be called the dead space, the $E$ curve have a long tail.

(3) If some fluid passes through the vessel in a

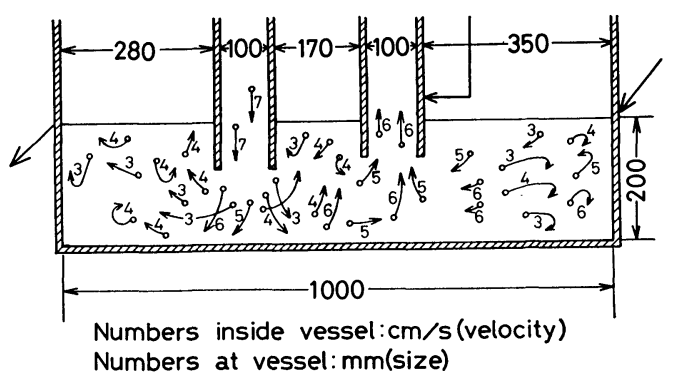

Fig. 9. Trajectory of the flow in the flow vessel by means of visual tracer (Two-dimensional plane). 
time of one tenth of the mean residence time of the overall fluid, this fluid can be said to bypass the vessel for all the practical purpose. The $E$ curve shows two peaks, but they would probably be indistinct in the actual cases and would not be easy to distinguish.

The $E$ curves under the following conditions are shown in Fig. 10: a flow rate is $7.2 \mathrm{l} / \mathrm{min}$, circulating rates in the vacuum vessel are $70 \mathrm{l} / \mathrm{min}, 50 \mathrm{l} / \mathrm{min}$ and $30 \mathrm{l} / \mathrm{min}$, and the up-leg is placed on the inlet side of the flow vessel. This figure shows the facts that the degree of mixing increases appreciably with increases in the circulating rate, and the shape after the each peak is almost an exponential decay curve. Themelis has assumed that the reactor volume may be divided into fractions, to each of which simple well-defined flow patterns, such as perfect mixing, plug flow and dead space, are assigned. ${ }^{29)}$ His simplified model of mixing shows that a very large fraction of the model degassing reactor (92\%) behaves as the perfect mixing volume at the circulating rates of $70 \mathrm{l} / \mathrm{min}$ and $50 \mathrm{l} / \mathrm{min}$, and the plug flow region is scarce. The residual region may be occupied by the dead space. At a circulating rate of $30 \mathrm{l} / \mathrm{min}$, the reactor volume fraction of $4 \%$ is a plug flow region and the degree of mixing becomes a little smaller. It may be safely said that the reactor has almost perfect mixing.

The $E$ curves under the following conditions are shown in Fig. 11: the flow rate is $20 \mathrm{l} / \mathrm{min}$, the circulating rates in the vacuum vessel are $70 \mathrm{l} / \mathrm{min}, 50 \mathrm{l} / \mathrm{min}$ and $30 \mathrm{l} / \mathrm{min}$, and the up-leg is placed on the inlet side of the flow vessel. The shape of the curve at a circulating rate of $50 \mathrm{l} / \mathrm{min}$ is almost same as that at $70 \mathrm{l} / \mathrm{min}$, and they show the exponential decay after the peaks of the curves. A portion of the volume occupied by plug flow at a flow rate of $20 \mathrm{l} / \mathrm{min}$ was $6 \%$ of the overall volume and it was a little larger than that at flow rate of $7.2 \mathrm{l} / \mathrm{min}$. In this case, the reactor is of almost perfect mixing. At a circulating rate of $30 \mathrm{l} / \mathrm{min}$, the shape of the residence time distribution function is different from those at $50 \mathrm{l} / \mathrm{min}$ and $70 \mathrm{l} / \mathrm{min}$. There are two peaks in it, and as mentioned earlier in this chapter, they will show the existence of the bypass flow and the cross flow. A long tailing of the $E$ curve will show the existence of the dead space.

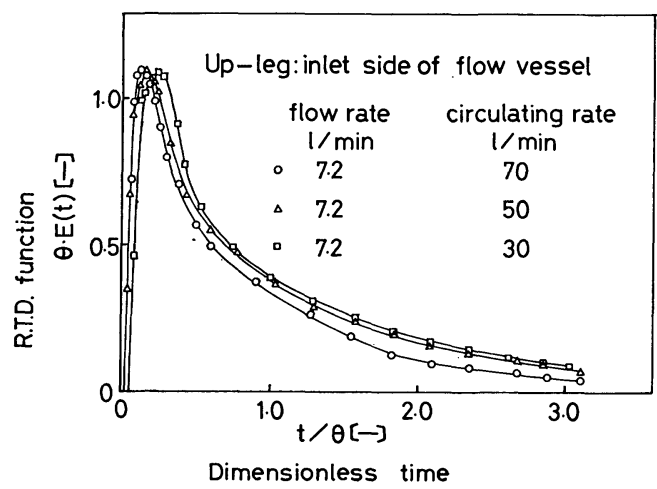

Fig. 10. Concentration-time curve for pulse input in model degassing reactor. (1)
When the flow rate is $7.2 \mathrm{l} / \mathrm{min}$, the circulating rates are $70 \mathrm{l} / \mathrm{min}$ and $30 \mathrm{l} / \mathrm{min}$, respectively, and the up-leg is placed on the outlet side of the flow vessel, then the $E$ curve is shown in Fig. 12. The degree of mixing in this case is much larger than that where the up-leg is placed on the inlet side of the flow vessel. Owing to the small flow rate, the influence of the circulation on the degree of mixing is very large and the concentration-time curve rises almost perpendicularly from the origin. The comparison of peak heights shows the fact that the fraction of the bypass flow decreases as the circulating rate increases. Being excepted a very narrow region $(t / \theta=0.02 \sim 0.04)$ quite near the origin from which the curve rises, the concentration-time curves almost agree to the ideal perfect mixing $E(t)=e^{-t / \theta} / \theta$.

When the operation was performed at a flow rate of $20 \mathrm{l} / \mathrm{min}$ and at a circulating rate of either $70 \mathrm{l} / \mathrm{min}$ or $50 \mathrm{l} / \mathrm{min}$, on the condition that the up-leg is placed on the outlet side of the flow vessel, these results are shown in Fig. 13. In comparison with Fig. 12, the larger influence of the flow rate appears in Fig. 13, from which it is estimated that the plug flow ratio

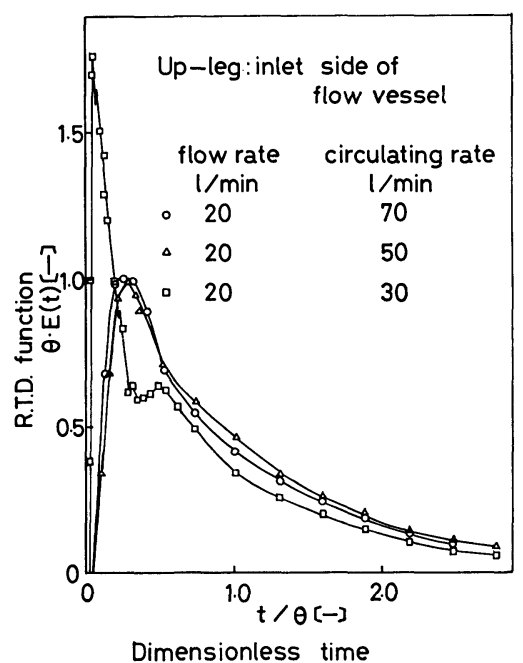

Fig. 11. Concentration-time curve for pulse input in model degassing reactor. (2)

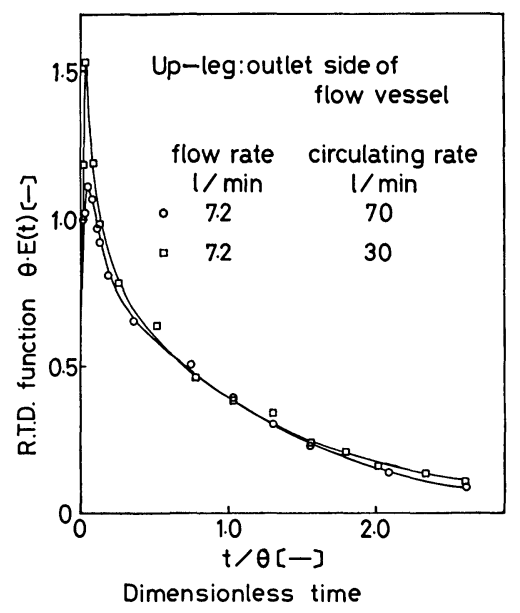

Fig. 12. Concentration-time curve for pulse input in model degassing reactor. (3) 
is 0.02 for the circulating rate of $70 \mathrm{l} / \mathrm{min}$ and 0.03 for $50 \mathrm{l} / \mathrm{min}$, respectively. Being excepted the initial stage where the curves rise, the residence time distribution functions show the exponential decay which means the perfect mixing.

The experimental values should be compared with the theoretical ones under the condition that the upleg is placed on the inlet side of the flow vessel. There is a term of the plug flow in the theoretical model. If this flow is not disturbed, the experimental results are expected to be similar to those obtained from the theoretical model. In practice, as may be seen in Fig. 9, the flow is considerably disturbed. The concentration-time curve rises at a position a little far from the origin owing to the plug flow, and the peak (maximum value) appears in the situation with the top disturbed. Both the position of the peak and the decaying shape of the curve are important, and the practical curve and the theoretical curve resemble each other in shape behind the peak. The difference to this extent, however, may often be seen between the practice and the theory, ${ }^{26)}$ and it may be said that the theory is almost equal to the practice. The comparison of the theory with the practice is done on the condition that the up-leg is placed on the outlet side of the flow vessel. $\delta$ function is introduced in the theoretical derivation. The smaller a circulating rate is, i.e., the smaller a ratio of the circulating rate to the flow rate is, the larger a deviation of the practice from the theory is. If the height of area $v / v_{2}$ is the same with the experimental value at the position where $\delta$ function appears, the width of area $v / v_{2}$ is almost equal to the distance between the origin and the rising position of the curve. Because the theoretical flow pattern is disturbed in the real flow, the measured distribution curve becomes smooth, and a sharp peak appears owing to the presence of $\delta$ function. Namely, it may be said that the residence time distribution function in the reactor can be represented irrespective of the position of the up-leg by Eq. (3).

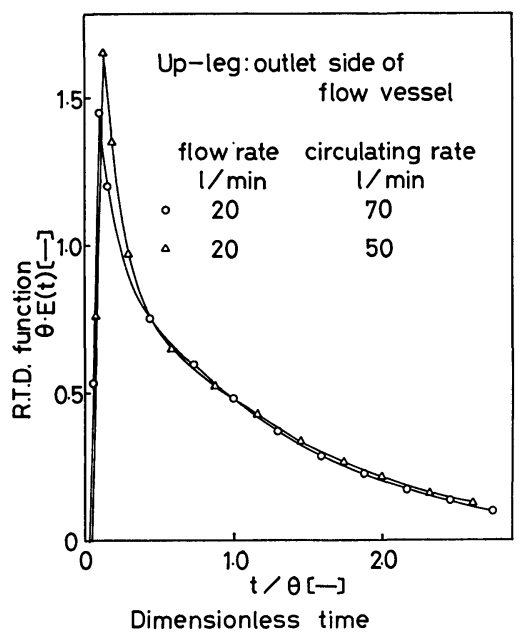

Fig. 13. Concentration-time curve for pulse input in model degassing reactor. (4)

\section{Estimation of Degassing Rate on Continuous Operation}

When the residence time distribution function is given and the reaction rate on the batch operation is known, the percent conversion $\langle C\rangle /[C]_{\text {in }}$ on the continuous operation can be estimated using Eq. (7) under the assumption that the reaction is of first order or the flow is of macro-mixing.

$$
\frac{\langle C\rangle}{[C]_{\text {in }}}=\int_{0}^{\infty} \frac{\langle C\rangle}{[C]_{\text {in }}} \cdot E(t) d t
$$

The residence time distribution in the continuous degassing reactor are represented theoretically by either Eq. (3) or Eq. (5), but it is desirable that the residence time distribution function is as simple as possible for the purpose of the kinetic calculation.

In calculation of the percent conversion on the continuous degassing operation, the following items were assumed.

(1) Mixing in the reactor is of perfect mixing.

(2) There is neither agglomeration nor fission of bubbles and the reactor is of macro-mixing.

(3) The degassing by bubbles is rate-controlled by the mass transfer in the metal at the surface of the molten steel.

The rate equation of degassing (the removal of hydrogen, nitrogen and oxygen) in the molten steel is generally shown by Eq. (8). ${ }^{30}$ )

$$
2.303 \log \frac{[C]-[C]_{\mathrm{int}}}{[C]_{\mathrm{in}}-[C]_{\mathrm{int}}}=-k_{a} \cdot t
$$

where, $[C]_{\text {in }}$ : initial concentration of gas in molten steel

$[C]$ : concentration of the bulk at time $t$,

$[C]_{\text {int }}$ : interface concentration

$k_{a}\left[T^{-1}\right]$ : capacity coefficient

For hydrogen, ${ }^{30,31)}$ the following equation (9) is valid.

$$
\left.\begin{array}{rl}
{[G]_{\mathrm{int}}} & =\kappa_{\mathrm{H}} \sqrt{p_{\mathrm{H}_{2}}} \\
\kappa_{\mathrm{H}} & =[\% \mathrm{H}] / \sqrt{p_{\mathrm{H}_{2}}(\mathrm{~atm})} \\
k_{a} & =0.4 \sim 3.0 \times 10^{-3}\left[\mathrm{~s}^{-1}\right] \\
\log K_{\mathrm{H}} & =-1905 / T-1.591
\end{array}\right\}
$$

For oxygen, ${ }^{30,32)}$ the following equation $(10)$ is valid.

$$
\begin{aligned}
{[\mathrm{G}]_{\mathrm{int}} } & =-\frac{1}{2}\left(\frac{16}{12}[\mathrm{G}]_{\mathrm{in}}-[\mathrm{O}]_{\mathrm{in}}\right) \\
& +\sqrt{\frac{1}{4}\left(\frac{16}{12}[\mathrm{G}]_{\mathrm{in}}-[\mathrm{O}]_{\mathrm{in}}\right)^{2}+\frac{12}{16} \frac{p_{\mathrm{co}}}{k_{\mathrm{CO}}}}
\end{aligned}
$$

where, $[\mathrm{C}]_{\text {in }}$ : initial concentration of carbon

$[\mathrm{O}]_{\mathrm{in}}$ : initial concentration of oxygen

$$
\begin{aligned}
k_{\mathrm{CO}} & =\frac{p_{\mathrm{CO}}}{a_{\underline{\mathrm{C}}} \cdot a_{\underline{\mathrm{O}}}}, \\
\log \kappa_{\mathrm{Co}} & =1160 / T+2.003 \\
k_{a} & =0.5 \sim 2 \times 10^{-3}\left[\mathrm{~s}^{-1}\right]
\end{aligned}
$$

By rewriting Eq. (8), Eq. (11) is obtained. 


$$
[C]=\left([C]_{\mathrm{in}}-[C]_{\mathrm{int}}\right) \exp \left(-k_{a} \cdot t\right)+[C]_{\mathrm{int}}
$$

By substituting Eq. (11) into Eq. (7), Eq. (12) is obtained.

$$
\langle C\rangle=\left([C]_{\mathrm{in}}-[C]_{\mathrm{int}}\right) \int_{0}^{\infty} \exp \left(-k_{a} \cdot t\right) \cdot E(t) d t+[C]_{\mathrm{int}}
$$

$k_{a}$ in Eq. (12) is the quantity defined in a circulating vessel with the weight $W_{1}$ (or the volume $V_{1}$ ) (strictly of the up-leg and the vacuum vessel) in which degassing takes place. Since no reactions take place in the flow vessel with the weight $W_{2}$ (or the volume $V_{2}$ ), the following corrected capacity coefficient $k_{a}^{\prime}$ must be adopted in place of $k_{a}$.

$$
k_{a}^{\prime}=\frac{W_{1}}{W_{1}+W_{2}} k_{a}=\frac{V_{1}}{V_{1}+V_{2}} k_{a}
$$

As mentioned above, the percent conversion is calculated as follows. On the operation of single stage,

$$
\langle C\rangle=\frac{[C]_{\mathrm{in}}-[C]_{\mathrm{int}}}{k_{a}^{\prime} \cdot \theta+1}+[C]_{\mathrm{int}}
$$

On the operation of $n$ stages,

$$
\langle C\rangle=\frac{[C]_{\mathrm{in}}-[C]_{\mathrm{int}}}{\left(k_{a}^{\prime} \theta / n+1\right)^{n}}+[C]_{\mathrm{int}}
$$

The calculated values of Eqs. (14) and (15) are shown in Table 2. It is assumed that the removal of hydrogen is carried out in the killed steel. In comparison with $\mathrm{RH}$ process which aims at the hydrogen level of $1 \sim 2 \mathrm{ppm}$, the continuous degassing process requires two stage reactors in which the total mean residence time is $40 \mathrm{~min}$. In the same table, it is assumed that the removal of oxygen is performed for nondeoxidized steel. The supplied steel is required to be preliminary decreased to $90 \mathrm{ppm}$ in the oxygen content, in order to attain the oxygen content of $50 \mathrm{ppm}$ after the two stage treatment.

For a comparative study, the percent conversion is derived from the material balance. The result is shown in Eq. (16) for single stage operation.

$$
\begin{aligned}
\langle C\rangle & =\frac{[C]_{\mathrm{in}}-[C]_{\mathrm{int}}}{\frac{v_{1} \cdot k_{a} \cdot V_{1}}{v\left(v_{1}+k_{a} \cdot V_{1}\right)}+1}+[C]_{\mathrm{int}} \\
& =\frac{[C]_{\mathrm{in}}-[C]_{\mathrm{int}}}{k_{a} \cdot \frac{V_{1}}{V_{1}+V_{2}} \cdot \theta \frac{v_{1}}{v_{1}+k_{a} \cdot V_{1}}+1}
\end{aligned}
$$

In Eq. (16), $V_{1} /\left(V_{1}+V_{2}\right)$ is a correction factor for $k_{a}$ and $v_{1} /\left(v_{1}+k_{a} \cdot v_{1}\right)$ a correction factor for $\theta$.

By substituting the experimental variables, such as the flow rate $(v)$ of $7.2 \mathrm{l} / \mathrm{min}$, the circulating rate $\left(v_{1}\right)$ of $70 \mathrm{l} / \mathrm{min}$, the volume of the circulating vessel $\left(V_{1}\right)$ of $90 \mathrm{l} / \mathrm{min}$ and the volume of the flow vessel $\left(V_{2}\right)$ of $48 l$ into Eq. (16), the calculated value of $\langle C\rangle$ is $3.18 \mathrm{ppm}$ for the removal of hydrogen in the single stage reactor. Compared this value with that in Table 2, the former shows a higher value by $10 \%$ than the latter.

\section{Conclusion}

(1) Residence time distribution function $E(t)$ in a continuous degassing reactor was theoretically derived from the assumption that the mixing in the reactor is expressed as circulation model with plug flow and perfect mixing.

The equation was shown as follows:

$$
\begin{gathered}
E(t)=d \sum_{n=0}^{\infty} \frac{b^{n}}{n !}\{t-(h+n c)\}^{n} \cdot \exp [-a\{t-(h+n c)\}] \\
t \geqq h+n c
\end{gathered}
$$

\begin{tabular}{|c|c|c|c|c|c|}
\hline & Hydrogen & Hydrogen & Hydrogen & Oxygen & Oxygen \\
\hline Capacity coefficient $k_{a^{\prime}}\left[\mathrm{min}^{-1}\right]^{*}$ & $102 \times 10^{-3}$ & $102 \times 10^{-3}$ & $102 \times 10^{-3}$ & $78 \times 10^{-3}$ & $78 \times 10^{-3}$ \\
\hline \multirow[t]{2}{*}{ Concentration of feed $[C]_{\mathrm{in}}[\mathrm{ppm}]$} & \multirow[t]{2}{*}{7} & \multirow[t]{2}{*}{7} & \multirow[t]{2}{*}{7} & $\mathrm{G}: 1000$ & $\mathrm{G}: 1000$ \\
\hline & & & & $O: \quad 240$ & $O: \quad 240$ \\
\hline Concentration of interface $[C]_{\mathrm{int}}[\mathrm{ppm}]$ & 0.83 & 0.83 & 0.83 & 0.167 & 0.167 \\
\hline Mean residence time $\theta[\mathrm{min}]$ & 19.7 & 39.6 & 59.1 & 39.6 & 59.1 \\
\hline Number of unit $n[-]$ & 1 & 2 & 3 & 2 & 3 \\
\hline Concentration of product $\langle G\rangle[\mathrm{ppm}]$ & 2.88 & 1.51 & 1.06 & 140 & 107 \\
\hline Percent conversion $[\%]$ & 58.8 & 78.4 & 84.8 & 41.7 & 55.4 \\
\hline
\end{tabular}

The coefficients were determined by the flow rate $(v)$ at the inlet, the circulating rate $\left(v_{1}\right)$, the real flow rate $\left(v_{2}\right)$ in the flow vessel, the volume of the circulating vessel $\left(V_{1}\right)$, and the volume of the flow vessel $\left(V_{2}\right)$.

The coefficients are shown as follows:

$$
\begin{aligned}
\theta_{\mathrm{C}} & =\frac{V_{1}}{v_{1}}, \quad \theta_{\mathrm{B}}=\frac{V_{2}}{v_{2}}, \quad a=\frac{1}{(1-p) \theta_{\mathrm{C}}} \\
b & =\frac{v_{2}}{v_{1}(1-p) \theta_{\mathrm{C}}}, \quad c=p \cdot \theta_{\mathrm{C}}+\theta_{\mathrm{B}} \\
d & =\frac{v}{v_{1}(1-p) \theta_{\mathrm{C}}}, \quad h=p \cdot \theta_{\mathrm{C}}
\end{aligned}
$$

Table 2. Some calculation results on continuous degassing.

* Mean value of published capacity coefficient, including correction factor. 
where, $p$ : the plug flow ratio in the circulating vessel.

(2) Mixing characteristics in the model apparatus were measured by means of the concentration pulse response under the condition of similarity of $\mathrm{Fr}$ and $R e$ numbers. The results of the measurement of the pulse response and the tracing of the flow pattern have revealed the presence of minor parts of bypass flow and dead space, and showed relatively close agreement with the above-mentioned theoretical equation.

(3) From these results, the percent conversion on continuous degassing operation, assuming that perfect mixing is dominant in the reactor, was estimated and it was in approximate agreement with the results on $\mathrm{RH}$ degassing operation when the mean residence time was properly selected (40 min) and two unit reactors at least were connected in series.

\section{Acknowledgements}

In performance of this research, we had useful discussion by Prof. Dr. T. Miyauchi of The University of Tokyo and Dr. A. Fukuzawa of NRIM. In this place, we would express our cordial thanks to them.

\section{REFERENCES}

1) R. Nakagawa, S. Yoshimatsu, T. Ueda, T. Mitsui, A. Fukuzawa, A. Satō and T. Ozaki: Tetsu-to-Hagané, 59 (1973), 414.

2) T. Mitsui, R. Nakagawa, S. Yoshimatsu, T. Ueda, N. Nishimoto and K. Honda: Trans. NRIM, 16 (1973), 179.

3) T. Ueda, T. Mitsui, R. Nakagawa and S. Yoshimatsu: Nihon-Kōgyō-Kaishi (J. Mining Metal. Inst. Japan), 89 (1973), 473 and 545.

4) A. Fukuzawa, R. Nakagawa, S. Yoshimatsu and T. Ueda: Tetsu-to-Hagané, 63 (1977), 63.

5) A. Fukuzawa, R. Nakagawa, S. Yoshimatsu and T. Ueda: Tetsu-to-Hagané, 64 (1978), 1333.

6) T. Mitsui, T. Watanabe, Y. Iwai, Y. Endō, H. Sugimoto and H. Kojima: Taikabutsu (Refractories), 29 (1977), 291.

7) R. Nakagawa: Bull. Japan Inst. Metals, 17 (1978), 205.

8) Spe. Rep. No. 8 Development of Vacuum Melting and Vacuum Degassing Methods of Steel, ed. by ISIJ, (1969).

9) I. Muchi and A. Moriyama: Yakin-Hannō-Kōgaku (Reaction Kinetics in Metallurgy), Yōkendō, Tokyo, (1972).

10) Yakin-Kagaku-Kōgaku-Enshū (Exercise of Metallurgical Chemical Engineering), ed. by I. Muchi, Yōkendō, Tokyo, (1974).

11) N. Ōtsuki and M. Hattori: Fuji-Seitetsu-Gihō (Technical Report of Fuji Steel Corp.), 16 (1967), 224.

12) H. Watanabe, K. Asano and T. Saeki: Tetsu-to-Hagané, 54 (1968), 1327.

13) T. Fujii and I. Muchi: Tetsu-to-Hagané, 56 (1970), 558.

14) T. Fujii and I. Muchi: Tetsu-to-Hagané, 56 (1970), 1165.

15) A. Misawa and I. Muchi: Tetsu-to-Hagané, 56 (1970), 1687.

16) K. Narita and T. Makino: Tetsu-to-Hagané, 56 (1970), 1844 .

17) K. Nakanishi, J. Szekely and C. W. Chang: Ironmaking and Steelmaking, (1975), No. 2, 115.

18) Tokkyo-Shutsugan-Kōkoku (Public Announcement of Patent Application): 1968-No. 1749, 1975-No. 40083, and 1977-No. 115156.
19) Tokkyo-Shutsugan-Kōkoku (Public Announcement of Patent Application): 1958-No. 7504 and 1975-No. 1442.

20) Tokkyo-Shutsugan-Kōkoku (Public Announcement of Patent Application).

21) K. Sakurai, M. Nakayama, Y. Arima, N. Yamazaki and K. Asano: Fuji-Seitetsu-Gihō (Technical Report of Fuji Steel Corp.), 13 (1964), 597.

22) K. Kaneko, N. Asano and Y. Matsushita: Tetsu-to-Hagané, 62 (1976), 43.

23) N. Nakamura: Mokeiriron-to-Sukēruappu (Model Theory and Scale Up), Nikkan-Kōgyō-Shinbunsha, Tokyo, (1941), 135.

24) Spe. Rep. No. 12 A Handbook on Property of Liquid Iron and Slag, ed. by ISIJ, (1972), 8 and 41.

25) Kagaku Binran (Handbook of Chemistry), ed. by The Chemical Society of Japan, Maruzen, Tokyo, (1958), 474.

26) Y. Eguchi: Kagaku Kogaku (Chem. Eng. Japan), 26 (1962), 947.

27) G. Y. Wen and L. T. Fan: Models for Flow Systems and Chemical Reactors, Dekkar, New York, (1975).

28) D. M. Himmelbrau and K. B. Bischoff: Process Analysis and Simulation, John Wiley and Sons, Inc., (1968), 71.

29) N. J. Themelis and P. Spira: Trans. Met. Soc. AIME, 236 (1966), 821.

30) Manufacturing Techniques of Iron and Steel, Part I-Iron Making and Steel Making, ed. by ISIJ, Maruzen, Tokyo, (1972), 771 777.

31) Seikō-Hannō-no-Suishō-Heikōchi (Recommended Value in Steel-making), ed. by the No. 19 Comm., the Japan Society for the Promotion of Science, Nikkan-Kōgyō-Shinbunsha, Tokyo, (1968), 148.

32) Seikō-Hannō-no-Suishō-Heikōchi (Recommended Value in Steel-making), ed. by the No. 19 Comm., the Japan Society for the Promotion of Science, Nikkan-Kōgyō-Shinbunsha, Tokyo, (1968), 2.

\section{Supplement}

Derivation of transfer function in the concentration pulse response.

Case (1)

The case, when the up-leg of the circulating vessel is placed on the inlet side of the flow vessel. From Fig. 2,

$$
\begin{aligned}
v_{1} & =v+v_{2} \ldots \ldots \ldots \ldots \\
v \cdot C_{\text {in }} & =v_{1} \cdot C_{1}-v_{2} \cdot C_{2} .
\end{aligned}
$$

By performing Laplace transformation of Eq. (S-2),

$$
v \cdot C_{\mathrm{in}}(s)=v_{1} \cdot C_{1}(s)-v_{2} \cdot C_{2}(s)
$$

Transfer function $C_{\text {out }}(s) / C_{\text {in }}(s)$ for loop is shown as follows.

$$
W_{1}(s)=\frac{C_{\text {out }}(s)}{C_{\text {in }}(s)}=\frac{v \cdot C_{\text {out }}(s)}{v_{1} \cdot G_{1}(s)-v_{2} \cdot C_{2}(s)}
$$

where the volume of the circulating vessel is $V_{1}$, the volume of the flow vessel $V_{2}$.

$$
\theta_{\mathrm{C}}=\frac{V_{1}}{v_{1}}, \quad \theta_{\mathrm{B}}=\frac{V_{2}}{v_{2}}
$$

$p$ is the proportion of the volume occupied by the legs to the total volume of the circulating vessel, and the transfer function $W_{1}(\mathrm{~s})$ is given by $\mathrm{Eq}$. (S-6). 


$$
W_{1}(s)=\frac{\frac{v}{v_{1}(1-p) \theta_{\mathrm{C}}} \cdot \exp \left(-p \theta_{\mathrm{C}} \cdot s\right)}{s+\frac{1}{(1-p) \theta_{\mathrm{C}}}-\frac{v_{2}}{v_{1}(1-p) \theta_{\mathrm{C}}} \cdot \exp \left\{-\left(p \theta_{\mathrm{C}}+\theta_{\mathrm{B}}\right) s\right\}}
$$

The coefficients are shown as follows:

$$
\left.\begin{array}{ll}
\frac{1}{(1-p) \theta_{\mathrm{C}}}=a, & \frac{v_{2}}{v_{1}(1-p) \theta_{\mathrm{C}}}=b \\
p \cdot \theta_{\mathrm{C}}+\theta_{\mathrm{B}}=c, & \frac{v}{v_{1}(1-p) \theta_{\mathrm{C}}}=d \\
p \cdot \theta_{\mathrm{C}}=h &
\end{array}\right\}
$$

Substituting them into Eq. (S-6), and developing it into infinite series,

$$
W_{1}(s)=\frac{d \cdot \exp (-h \cdot s)}{s+a-b \exp (-c \cdot s)}=d \sum_{n=0}^{\infty} \frac{b^{n} \exp \{-(h+n c) s\}}{(s+a)^{n+1}}
$$

The residence time distribution function $E(t)$, namely, the impulse response is given by inverse Laplace transformation, $L^{-1}\left\{W_{1}(s)\right\}$.

$$
E(t)=L^{-1}\left\{W_{1}(s)\right\}
$$

Case (2)

The case, where the up-leg of the circulating vessel is placed on the outlet side of the flow vessel. In the very same way as in the case (1), transfer function $W_{\mathbf{2}}(s)$ is obtained from Fig. 3, as shown in Eq. (S-10).

$$
\begin{aligned}
W_{2}(s) & =\frac{v}{v_{2}} \exp \left(-\theta_{\mathrm{B}} \cdot s\right) \\
+ & \frac{\frac{v}{v_{2}} \frac{v_{1}}{v_{2}} \frac{1}{(1-p) \theta_{\mathrm{C}}} \exp \left\{-\left(p \cdot \theta_{\mathrm{C}}+2 \theta_{\mathrm{B}}\right) s\right\}}{s+\frac{1}{(1-p) \theta_{\mathrm{C}}}-\frac{v_{1}}{v_{2}} \frac{1}{(1-p) \theta_{\mathrm{C}}} \exp \left\{-\left(p \theta_{\mathrm{C}}+\theta_{\mathrm{B}}\right) s\right\}}
\end{aligned}
$$

The coefficients are shown as follows:

$$
\left.\begin{array}{l}
\frac{V_{2}}{v_{2}}=\theta_{\mathrm{B}}, \quad \frac{V_{1}}{v_{1}}=\theta_{\mathrm{C}}, \quad \frac{1}{(1-p) \theta_{\mathrm{C}}}=A \\
\frac{v_{1}}{v_{2}} \cdot \frac{1}{(1-p) \theta_{\mathrm{C}}}=B, \quad p \cdot \theta_{\mathrm{C}}+\theta_{\mathrm{B}}=C \\
\frac{v}{v_{2}} \cdot \frac{v_{1}}{v_{2}} \cdot \frac{1}{(1-p) \theta_{\mathrm{C}}}=D, \quad p \cdot \theta_{\mathrm{C}}+2 \theta_{\mathrm{B}}=H
\end{array}\right\}
$$

Substituting these coefficients into Eq. (S-10), and developing it into infinite series, the transfer function $W_{2}(s)$ is obtained as in Eq. (S-12).

$$
\begin{aligned}
W_{2}(s) & =\frac{v}{v_{2}} \cdot \exp \left(-\theta_{\mathrm{B}} \cdot s\right)+\frac{D \cdot \exp (-H \cdot s)}{s+A-B \cdot \exp (-C \cdot s)} \\
& =\frac{v}{v_{2}} \cdot \exp \left(-\theta_{\mathrm{B}} \cdot s\right)+D \sum_{n=0}^{\infty} \frac{B^{n} \cdot \exp \{-(H+n C) s\}}{(s+A)^{n+1}}
\end{aligned}
$$

The residence time distribution function $E(t)$, namely, the impulse response is given by inverse Laplace transformation $L^{-1}\left\{W_{2}(s)\right\}$.

$$
E(t)=L^{-1}\left\{W_{2}(s)\right\}
$$

